\title{
ATIVIDADE DE NIDIFICAÇÃO DE PHRYNOPS HILARII DUMÉRIL \& BIBRON (TESTUDINES, CHELIDAE) NA RESERVA BIOLÓGICA DO LAMI, RIO GRANDE DO SUL, BRASIL
}

\section{Clóvis Souza Bujes ${ }^{1}$}

\begin{abstract}
Nesting ACTIVITY OF PHRYNOPS HILARII DUMÉRIL \& Bibron (TESTUdINES, Chelidae) at the Lami Biological Reserve, Rio Grande do Sul, Brazil. Nesting activity of the neotropical turtle Phrynops hilarii Duméril \& Bibron, 1835 was studied from Feb/94 through Jan/95, with weekly visits at the Lami Biological Reserve $\left(30^{\circ} 15^{\prime} \mathrm{S}, 51^{\circ} 05^{\prime} \mathrm{W}\right)$, Porto Alegre, Rio Grande do Sul, Brazil. Nesting behavior was observed 17 times on three different nest sites. Phrynops hilarii laid in average 11 eggs per clutch (10-14; $s d \pm 1 ; n=17)$, nests' depth ranged from 100 to $150 \mathrm{~mm}(\mathrm{x}=121.53$ mm.sd $\pm 12.31 ; n=17)$. The species presents stereotiped behaviour common to other Testudines. Temperature inside the nest, just after nesting, ranged between $20-31^{\circ} \mathrm{C}$ $\left(x=26.29^{\circ} \mathrm{C} ; \mathrm{sd} \pm 2.89 ; \mathrm{n}=17\right)$; nest predation during this period was $82.35 \%$ ( 14 of 17 nests). From Aug/29 through Oct/03/95, 220 egg shells was collected next to 21 nests destructed by predators in the same sites. At the Reserve, the main nest predator is the nocturnal mammal Procyon cancrivorus Cuvier, 1798.

KEY WORDS. Testudines, Chelidae, Phrynops hilarii, egg predation, neotropical turtle, nesting behavior
\end{abstract}

No Rio Grande do Sul é registrada a ocorrência de seis espécies de testudines de águas continentais (LEMA 1994). Duas delas, Phrynops hilarii (Duméril \& Bibron, 1835), Chelidae, e Trachemys dorbigni (Duméril \& Bibron, 1835), Emydidae, são encontradas com relativa abundância na Reserva Biológica do Lami.

A Reserva Biológica do Lami é uma área de preservação municipal criada em 31 de dezembro de 1975, através do Decreto-lei n ${ }^{\circ} 4097$. Localiza-se na zona sul da cidade de Porto Alegre, às margens do Lago Guaíba $\left(30^{\circ} 15^{\prime} \mathrm{S}, 51^{\circ} 05^{\prime} \mathrm{W}\right)$. Possui uma área original de 77,3 ha. Atualmente está se incorporando à Reserva um pontal (Ponta do Cego), com cerca de 102,48 ha, dos quais cerca de $80 \%$ são constituídos de banhados e cerca de $15 \%$ por um morro, abrigando paisagens naturais das margens do Guaíba (BRACK et al. 1992).

O presente trabalho tem por objetivo estudar o comportamento de nidificação de $P$. hilarii em seu habitat e a existência de predadores de seus ovos, colaborando, desta forma, ao conhecimento da etologia da herpetofauna local, tão pouco estudada.

Phrynops hilarii, popularmente conhecida por cágado, possui carapaça achatada com escudos epidérmicos lisos, cuja coloração é cinza uniforme, contras-

1) Departamento de Zoologia, Instituto de Biociências, Universidade Federal do Rio Grande do Sul. 90046-900 Porto Alegre, Rio Grande do Sul, Brasil.

E-mail: csbujes@conex.com.br

Revta bras. Zool. 15 (4): 921 - 928, 1998 
tando com o plastrão, que é amarelo claro salpicado com pontos e manchas negras. Apresenta cinco unhas nos membros anteriores e quatro nos posteriores; membranas interdigitais bem desenvolvidas permitem a este cágado ágeis evoluções aquáticas (Fig. 1).

Segundo FrEIBERG (1967), põe de 10 a 12 ovos esféricos e de casca dura, em covas não muito profundas. Pode atingir até $360 \mathrm{~mm}$ de comprimento da carapaça. Ocorre na Argentina (da Província de Buenos Aires, pelo litoral do rio Paraná, até Misiones), sul do Paraguai, Uruguai e sul do Brasil (Rio Grande do Sul).

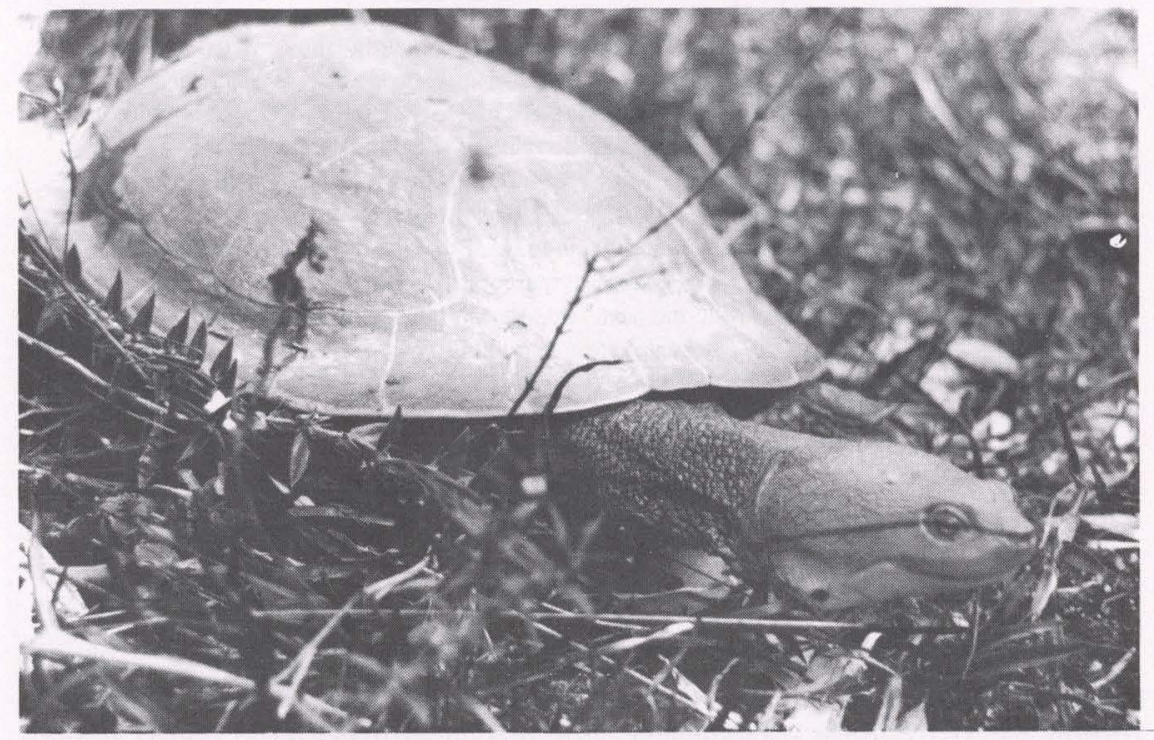

Fig. 1. Phrynops hilarii em seu ambiente, na Reserva Biológica do Lami. Individuo com 350mm de comprimento máximo da carapaça.

\section{MATERIAL E MÉTODOS}

\section{Descrição da área}

A Reserva Biológica do Lami caracteriza-se por apresentar uma diversidade de ambientes florísticos que vão desde banhados até áreas de restinga, com extensos areiais. Nestas áreas, o relevo é predominantemente plano. Entre as discretas elevações arenosas, surgem depressões onde se acumula água durante o período de chuvas, que podem ou não se manter até o verão. A vegetação pioneira de Dodonaea viscosa Jacq. (Sapindaceae) ("vassoural"), mesclada a cactáceas (Opuntia sp. e Cereus sp.) e gramíneas, é a mais abundante nestes pontos. Entre este tipo de vegetação herbáceo-arbustiva ocorrem áreas descobertas, cujo solo é arenoso e de coloração clara. São estas as áreas escolhidas por $P$. hilarii para nidificação.

Segundo MORENo (1961), o estado do Rio Grande do Sul possui clima do tipo subtropical com áreas restritas de clima do tipo temperado. Porto Alegre localiza-se na área climática cfa (subtropical úmido sem estação seca), com tempe- 
ratura média anual de $19,2^{\circ} \mathrm{C}$ (extremos 0,4 e $36,9^{\circ} \mathrm{C}$ ). A umidade relativa média do ar é de $76 \%$, e as máximas pluviométricas ocorrem nos meses de julho, setembro, outubro e dezembro, com médias em torno de $117,4 \mathrm{~mm}$, apesar das chuvas se distribuírem ao longo do ano.

\section{Metodologia}

Estabeleceu-se pontos de observação em três diferentes locais de nidificação, sítios $\mathrm{A}, \mathrm{B}$ e $\mathrm{C}$, os quais se distribuem ao longo de uma trilha principal que corta a reserva no sentido leste-oeste. Os três sítios possuem características muito similares: são extensões de areia clara, que drena rapidamente a água da chuva sem perder completamente a umidade; boa exposição ao sol; pouca cobertura vegetal; e, são separados entre si por capoeiras de vegetação arbustiva. Utilizou-se como critério de escolha destes sítios a abundância de fêmeas nidificando e a facilidade nas observações. Os sítios foram visitados semanalmente, de fevereiro/94 a janeiro/95.

As observações do hábito de nidificação foram executadas a uma distância aproximada de cinco metros, com auxílio de binóculos para evitar possíveis alterações no comportamento da fêmea. Tais registros foram descritivos e, quando possível, fotográficos. Era cronometrado o tempo de duração do ato de postura, contado a partir do primeiro avistamento da fêmea até o abandono do ninho. Terminada cada postura, imediatamente após a fêmea deixar o ninho, registravam-se os seguintes dados: temperaturas do ar (a $150 \mathrm{~cm}$ do solo), do substrato (ao nível do solo) e do interior do ninho; profundidade do ninho e quantidade de ovos. Quando havia necessidade, os ovos eram retirados e recolocados nos ninhos, na mesma posição em que se encontravam inicialmente. Os ninhos foram marcados e sua localização registrada em caderneta de campo.

Em uma segunda fase da pesquisa, entre 29/08 e 03/10/95, semanalmente, foram marcados os ninhos escavados por predadores de ovos; as cascas eram contadas e recolhidas do local, o que só era possível quando os predadores as deixavam próximas aos ninhos. Desta forma, se pretendia confrontar o número médio de cascas de ovos encontradas, com o número médio de ovos observado nos ninhos.

\section{RESULTADOS E DISCUSSÃO}

A atividade de nidificação de $P$. hilarii, observada na Reserva Biológica do Lami, ocorreu entre 18/08/94 e 11/01/95. Foram observadas 17 posturas e três deambulações sem efetiva construção de ninhos. A maioria dos ninhos foram escavados pela manhã $(76,47 \%)$. O abandono de ninho mais tardio se deu por volta das 16:20 horas (Tab. I). Destas posturas, duas foram realizadas em dia totalmente nublado (ninhos 4 e 5) e duas em dia chuvoso (ninhos 9 e 15). Destes ninhos, $82,35 \%$ (14 de 17 ninhos) foram destruídos por predadores.

Neste estudo, constatou-se que a espécie põe em média 11 ovos por ninho $(10-14, \mathrm{sd} \pm 1, \mathrm{n}=17)$. A profundidade dos ninhos variou de 100 a $150 \mathrm{~mm}(\mathrm{x}=121,53$ $\mathrm{mm}, \mathrm{sd} \pm 12,31, \mathrm{n}=17)$. A temperatura média no interior dos ninhos foi de $26,29^{\circ} \mathrm{C}$ $\left(20-31^{\circ} \mathrm{C}, \mathrm{sd} \pm 2,89, \mathrm{n}=17\right)$, enquanto que as temperaturas do ar e da superfície do 
solo ficaram em média de $25,59^{\circ} \mathrm{C}\left(18-30^{\circ} \mathrm{C}, \mathrm{sd} \pm 4,93, \mathrm{n}=17\right)$ e $30,59^{\circ} \mathrm{C}\left(21-42^{\circ} \mathrm{C}\right.$, $\mathrm{sd} \pm 28,28, \mathrm{n}=17)$, respectivamente. A relação das temperaturas do ambiente, da superfície do solo e do interior do ninho está representada na figura 2.

Tabela I. Relação das posturas de Phrynops hilarii observadas por sítios de nidificação (A, B e C). (TP) Tempo da postura - horário do primeiro avistamento da fêmea até esta abandonar o ninho, (PN) profundidade total do ninho, $(\mathrm{N})$ número de ovos por ninho.

\begin{tabular}{cclccc}
\hline Postura & Sítio & \multicolumn{1}{c}{ Data } & \multicolumn{1}{c}{ TP } & PN $(\mathrm{mm})$ & N \\
\hline 1 & A & $18-$ VIII-94 & $09: 00-11: 05$ & 100 & 11 \\
2 & A & $01-\mid X-94$ & $12: 25-13: 45$ & 116 & 10 \\
3 & A & $15-\mid X-94$ & $08: 30-09: 40$ & 110 & 10 \\
4 & A & $24-X I-94$ & $07: 55-09: 45$ & 110 & 12 \\
5 & A & $24-X I-94$ & $07: 55-10: 15$ & 120 & 11 \\
6 & A & $15-X I I-94$ & $13: 30-15: 00$ & 120 & 11 \\
7 & A & $04-\mid-95$ & $08: 00-09: 45$ & 125 & 14 \\
8 & B & $06-X-94$ & $10: 30-12: 00$ & 120 & 11 \\
9 & B & $17-X I-94$ & $09: 20-10: 40$ & 110 & 11 \\
10 & B & $22-X I I-94$ & $09: 00-10: 30$ & 120 & 11 \\
11 & B & $04-I-95$ & $10: 30-11: 00$ & 120 & 10 \\
12 & B & $11-I-95$ & $07: 45-09: 00$ & 140 & 11 \\
13 & C & $22-\mid X-94$ & $13: 00-13: 40$ & 120 & 11 \\
14 & C & $10-X-94$ & $08: 05-09: 23$ & 120 & 10 \\
15 & C & $17-X I-94$ & $08: 10-09: 07$ & 125 & 11 \\
16 & C & $15-X I I-94$ & $10: 15-11: 30$ & 150 & 10 \\
17 & C & $15-X I I-94$ & $15: 30-16: 20$ & 140 & 12 \\
\hline
\end{tabular}

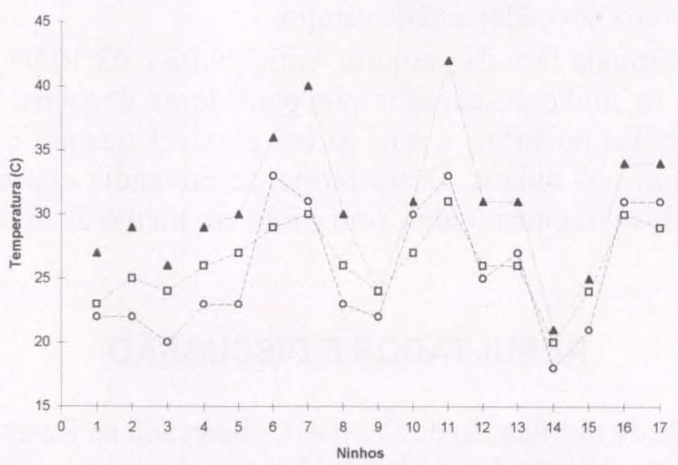

Fig. 2. Temperaturas do ar (círculos), da superficie do solo (triângulos) e do interior dos ninhos (quadrados) registradas logo após o término das posturas de Phrynops hilarii realizadas entre agosto/94 e janeiro/95 na Reserva Biológica do Lami. Os ninhos foram ordenados numericamente e não de acordo com a data da postura; as letras indicam os sitios de nidificação.

Na segunda fase do estudo, foram coletadas 220 cascas de ovos junto a 21 ninhos escavados por predadores, sendo 96 cascas ( 10 ninhos) no sítio A, 69 cascas (seis ninhos) no B e 55 cascas (cinco ninhos) no sítio C. Neste caso, obteve-se uma média de 10,48 ovos por ninho, valor corroborado pelo número médio de ovos encontrados na contagem direta das posturas. 
Astort (1984), estudando $P$. hilarii em cativeiro, sugere a ocorrência de dois períodos reprodutivos anuais, o primeiro, entre outubro e novembro e, o segundo, entre fevereiro e março. Relata ainda que todos os ninhos foram construídos pela manhã. Na Reserva Biológica do Lami somente 76,47\% dos ninhos observados foram construídos pela manhã e não se verificou a existência de dois períodos reprodutivos. GUIX et al. (1989) estudaram a espécie P. geoffroanus (Schweigger, 1812) em cativeiro e verificaram que a nidificação ocorre entre março e setembro, sempre após às 15 horas.

Phrynops hilarii escava seus ninhos afastados da vegetação. Ocasionalmente, nidifica junto às pequenas touceiras de gramíneas, desde que tais locais possuam boa exposição ao sol. As áreas mais descobertas, sem associação direta com a vegetação, são preferenciais.

Para atingir as áreas abertas (sítios de nidificação), as fêmeas atravessam a vegetação fechada que margeia os corpos d'água e os separam dos areiais. Na maioria das vezes, elas são primeiramente ouvidas, devido ao barulho que fazem ao atritarem-se contra a folhagem do solo. Ao emergir da vegetação, a fêmea, muito atenta, pára na borda da mata com o pescoço totalmente protraído e acima da carapaça, direcionando a cabeça para ambos os lado do corpo, realizando intensos movimentos gulares. Após um pequeno intervalo imóvel, ela inicia a deambulação.

O comportamento de nidificação de $P$. hilarii também é estereotipado, como o de muitas espécies de testudines, subdividindo-se nas cinco fases propostas por diversos autores (VANZOLINI 1967; KrAUSE et al. 1982; AstORT 1984; GUIX et al. 1989; Molina 1989): 1) deambulação, 2) abertura da cova, 3) postura dos ovos, 4) fechamento da cova e, 5) abandono do ninho.

A deambulação consiste em caminhar lentamente pelo sítio, dando curtas paradas e farejando o substrato, possivelmente fazendo um reconhecimento do local. Após 20 a 40 minutos de deambulação, é escolhido um ponto. A fêmea então, executa movimentos circulares com o corpo sobre o solo. Isso parece estar relacionado com uma limpeza prévia do local, pois com este giro ela expõe a areia que, em alguns pontos, pode estar coberta de musgo. Em seguida, inicia a escavação.

A abertura da cova é realizada com movimentos alternados das patas posteriores. A princípio, são escavadas duas pequenas covas, uma por cada pata. Neste momento, a fêmea libera um líquido incolor que umedece o substrato. CAGLE (1950), Moll \& Legler (1971), KraUse et al. (1982) e Molina (1989) também fazem referência a tal líquido formulando diferentes hipóteses sobre sua função. Aceita-se, neste trabalho, que a função primordial deste líquido é auxiliar na escavação da cova: o solo dos sítios de nidificação na Reserva Biológica do Lami é bastante solto, o que, possivelmente, acarretaria um desmoronamento das paredes da cova durante sua abertura. Uma vez umidificada com o líquido, a areia torna-se maleável e facilmente trabalhada. As duas pequenas depressões iniciadas fusionamse e toda a areia retirada do interior da cova é depositada nas bordas da mesma. Com os movimentos alternados, a areia muitas vezes é atirada longe do ninho. Os ninhos de $P$. hilarii, bem como de outros testudines, conforme observado por KRAUSE et al. (1982) e MolinA (1989), são constituídos de duas porções distintas: pescoço e 
câmara de incubação. Após concluída a escavação do ninho, tem início a postura dos ovos.

Durante a postura, a fêmea permanece imóvel, com a cabeça paralela em relação ao nível do solo e o corpo levemente inclinado para dentro do ninho. Realiza rápidos e incessantes movimentos gulares. Não foi possível observar se $P$. hilarii, a exemplo de $P$. geoffroanus (MoLINA 1989), acomoda os ovos no interior da câmara de incubação com o auxílio das patas. Verificar o período de tempo gasto para todo o processo de nidificação também ficou prejudicado, pois muitas vezes a fêmea era encontrada nas fases finais de nidificação. KRAUSE et al. (1982) registraram que Trachemys dorbignyi alterna camada de ovos com camada de areia; tal fato não foi registrado em $P$. hilarii, seus ovos são postos um sobre o outro de maneira a ocupar toda a câmara de incubação. Observou-se em quatro ninhos $(4,7,11$ e 13) que o pescoço também continha ovos. Uma vez iniciada a postura, a fêmea jamais abandona o ninho. A desistência em nidificar pode ocorrer durante as fases de deambulação e abertura da cova se a fêmea for perturbada, o que a faz voltar imediatamente à água.

Da mesma forma que ocorreu na abertura da cova, o ninho é fechado por movimentos alternados dos membros posteriores, com o material retirado de seu interior. A fêmea compacta a superfície do ninho com movimentos de plastrão contra o solo. Em algumas ocasiões, observou-se que a camuflagem do ninho se deu por recolhimento de material como musgo e folhas secas que se acumulam junto aos tufos de vegetação próximos a cova. Este material era recolhido com auxílio dos membros anteriores, e então compactados com o plastrão sobre o ninho. $\mathrm{O}$ abandono do ninho após, o fechamento da cova, ocorre de maneira rápida. A fêmea se dirige à água seguindo, na maioria das vezes, a mesma trilha que abriu na vegetação.

Verificou-se que $P$. hilarii nidifica solitariamente; de modo que somente duas fêmeas foram observadas nidificando no mesmo sítio, ao mesmo tempo (ninhos 4 e 5$)$.

Observou-se que os ninhos de $P$. hilarii, na Reserva Biológica do Lami, sofrem pressão de três predadores principais, um diurno, o lagarto-do-papo-amarelo, Tupinambis merianae (Duméril \& Bibron, 1839), que consome os ovos totalmente, inclusive com as cascas, e os mamíferos noturnos, graxaim-do-campo, Pseudalopex gymnocercus (Fischer, 1814), e mão-pelada, Procyon cancrivorus (Cuvier, 1798). Este último deixa como indícios de sua predação, além de pegadas, as cascas dos ovos com um furo por onde obtém o seu conteúdo (Fig. 3).

A partir de três posturas $(6,16$ e 17$)$ realizadas em $15 / 12 / 94$, que na manhã seguinte estavam predadas por mão-pelada, suspeitou-se que o mamifero encontrasse e escavasse o ninho provavelmente nas primeiras 24 horas após a postura, possivelmente atraído pelo cheiro do líquido expelido pela fêmea, ou ainda pela própria alteração do substrato revolvido. No entanto, Santos (comunicação pessoal), trabalhando na mesma Reserva, relata que encontrou, no conteúdo fecal do mãopelada, plastrões de embriões de $P$. hilarii, em diferentes estágios de desenvolvimento, o que nos faz rejeitar a hipótese levantada. Este autor encontrou sete grupos de alimentos na dieta do mão-pelada, sendo $9 \%$ filhotes de $P$. hilarii. 
Entre as 220 cascas de ovos predados por mão-pelada, somente um ovo foi encontrado inteiro, sobre o substrato, entre as demais cascas. Com base nestas observações verificou-se que, nos sítios de estudo, a destruição dos ninhos e o consumo dos ovos é efetivo. A predação ocorre ao longo de todo o ano, principalmente nos períodos de outono e inverno, quando é menor a oferta de frutos e sementes (M. de F. Santos comunicação pessoal), alimentos preferenciais do mão-pelada.

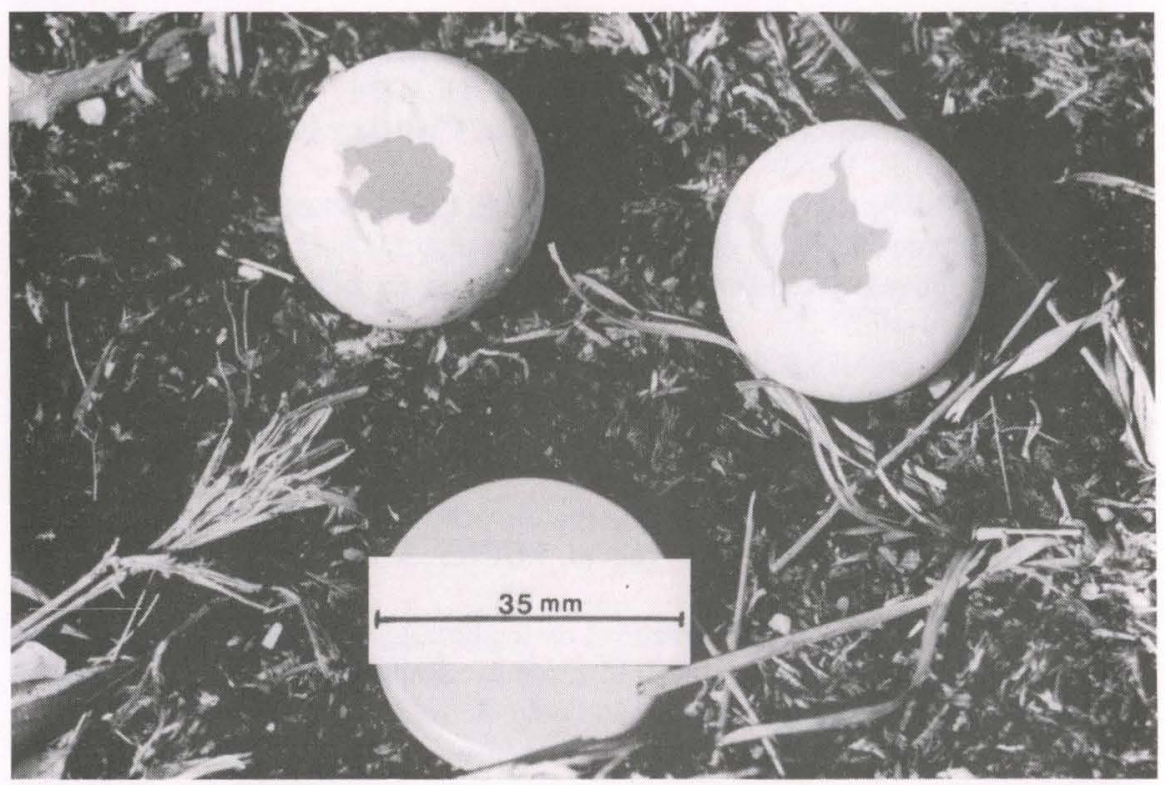

Fig. 3. Ovos de Phrynops hilarii predados por mão-pelada, Procyon cancrivorus, mostrando o orifício característico deixado por este predador.

\section{CONCLUSÕES}

Os cágados $P$. hilarii têm hábito de nidificação solitário, obedecendo às seguintes fases: 1) deambulação, 2) abertura da cova, 3) postura dos ovos, 4) fechamento da cova e, 5) abandono do ninho. Na Reserva Biológica do Lami, a nidificação ocorre entre agosto e fevereiro, sendo postos, em média, 11 ovos por ninho. Os ninhos são constituídos de pescoço e câmara de incubação, atingindo profundidade entre 100 e $150 \mathrm{~mm}$.

Um predador de ninhos de grande importância na Reserva é o mamífero Procyon cancrivorus (mão-pelada), que destrói os ninhos e consome os ovos de maneira efetiva.

AGRADECIMENTOS. A todas as pessoas que tornaram possivel, direta e indiretamente, a realização deste estudo; a Secretaria de Meio Ambiente da Prefeitura Municipal de Porto Alegre; ao Setor de Herpetologia do Departamento de Zoologia da UFRGS. 


\section{REFERÊNCIAS BIBLIOGRÁFICAS}

AstorT, E.D. 1984. Dimorfismo sexual secundario de Phrynops (Phrynops) hilarii (D. y B., 1835) y su conducta reproductora en cautiverio (Testudines-Chelidae). Revta. Mus. Arg. Cienc. Nat. B. Rivadavia, Zool., Buenos Aires, 13 (9): 107-113.

Brack, P.; J. Prates \& M.F.M. Santos. 1992. Guia de campo das espécies da Reserva Biológica do Lami. Sec. Mun. do Meio Ambiente de Porto Alegre, p.1-39.

CAGLE, F.R. 1950. The life history of the slider turtle, Pseudemys scripta troostii (Holbrook). Ecol. Monogr., New York, 20 (1): 31-54.

FREIBERG, M.A. 1967. Tortugas de la Argentina. Ciencia y investigación, Buenos Aires, 23 (8): 351-363.

GuiX, J.C.C.; M. SAlvatTi; M.A. Peroni \& J.S. Lima-Verde. 1989. Aspectos da reprodução de Phrynops geoffroanus (Schweigger, 1812) em cativeiro (Testudines-Chelidae). Série Documentos do Grupo de Estudos Ecológicos, São Paulo, (1): 1-19.

KRAUSE, L.; N. GOMES \& K.L. LeYSER. 1982. Observações sobre a nidificação e desenvolvimento de Chrysemys dorbignyi (Duméril \& Bibron, 1835) (Testudines, Emydidae) na Estação Ecológica do Taim, Rio Grande do Sul. Revta bras. Zool. 1 (1): 79-90.

LEMA, T. 1994. Lista comentada dos répteis ocorrentes no Rio Grande do Sul, Brasil. Comun. Mus. Ciênc. Tecnol. PUCRS, Série Zool., Porto Alegre, 7: 41-150.

MolinA, F.B. 1989. Some observations on the biology and behavior of Phrynops geoffroanus (Schweigger, 1812) in captivity (Reptilia, Testudines, Chelidae). Grupo Estud. Ecol. Ser. Doc., São Paulo, 3: 35-37.

MoLL, E.O. \& J.M. LEGLER. 1971. The life history of a neotropical slider turtle, Pseudemys scripta (Schoepff) in Panama. Bull. Los Angeles Co. Mus. Nat. Hist. Sci. (11): 1-102.

Moreno, J.A. 1961. Clima do Rio Grande do Sul. Boletim Geográfico 6 (11): 49-73.

VANZOLINI, P.E. 1967. Notes on the nesting behaviour of Podocnemis expansa in the Amazon Valley (Testudines, Pelomedusidae). Papéis Avuls Dept. Zool., São Paulo, 20 (17): 191-215.

Recebido em 15.V.1997; aceito em 03.XI.1998. 